\title{
OPTIMALISASI PENERAPAN TEKNOLOGI VIRTUAL REALITY TOUR KAMPUS UNIVERSITAS MAJALENGKA MENGGUNAKAN METODE MULTIMEDIA DEVELOPMENT LIFE CYCLE
}

\author{
Tri Ferga Prasetyo ${ }^{1}$, Ade Bastian ${ }^{2}$ Harun Sujadi $^{3}$ \\ 1,2,3 Program Studi Informatika, Fakultas Teknik, Universitas Majalengka \\ Email: $\underline{1 \text { triferga.prasetyo@gmail.com, }}, \underline{\text { bastiandicaprio@gmail.com, }}{ }^{3}$ harunsujadi@gmail.com
}

\begin{abstract}
ABSTRAK
Campus introduction media in general still use billboards and brochures or advertisements, therefore the use of Virtual Reality technology is very good to use. Optimizing the application of this technology is made to build an interactive application that can visualize the facilities and infrastructure at University Majalengka in the form of 360 images and videos to make it easier for users to digitally view the facilities and infrastructure of the University Majalengka Campus. The method used in this research is MDLC (Multimedia Development Life Cycle). This method can optimize the manufacturing process and application of technology used in a smartphone media that is integrated with other media or 3D media. MDLC rule pattern itself by prioritizing interactive rests on the user. This application was built using the $C$ \# programming language with Unity $3 D$ software. The final result of this research is the creation of a virtual tour application of the University Majalengka Campus which can be used by users to view interactive digital facilities and infrastructure on campus with a 360 degree angle using a smartphone that has a Gyroscope sensor which can be integrated with the paired virtual reality technology. into virtual reality glasses.
\end{abstract}

keywords: Campus Introduction Media, Virtual Reality, Multimedia Development Life Cycle, Gyroscope sensor, smartphone

\section{PENDAHULUAN}

1.1. Latar Belakang

Perkembangan teknologi yang sudah sangat modern ini menimbulkan pengaruh yang besar ke berbagai aspek kehidupan. Mempengaruhi berbagai bidang dalam kehidupan manusia. Hal ini dikarenakan perkembangan teknologi yang semakin hari semakin tumbuh pesat, sehingga memunculkan banyak inovasi-inovasi baru di bidang teknologi. Salah satu inovasi dari bidang teknologi yang terkenal pada tahun 2016 lalu adalah Virtual Reality atau biasa disingkat VR(Riyadi, F.S, dkk, 2017).

Virtual Reality adalah sebuah teknologi yang membuat pengguna atau user dapat berinteraksi dengan lingkungan yang ada dalam dunia maya yang disimulasikan oleh komputer, sehingga pengguna merasa berada di dalam lingkungan tersebut. Di dalam bahasa Indonesia virtual reality dikenal dengan istilah realitas maya.

Perkembangan teknologi yang saat ini berkembang semakin hari semakin pesat, sehingga memunculkan banyak inovasi baru dari teknologi Virtual Reality, salah satu inovasi yang dapat kita jumpai teknologi yang berkembang saat ini adalah teknologi Virtual Tour. Dalam jurnal yang disusun oleh Osman, Wahab dan Ismail (2009, p173), Virtual Tour merupakan teknologi yang menempatkan user didalam gambar atau video dan memungkinkan user untuk meningkatkan kesadaran situasional serta meningkatkan daya lihat, tangkap dan menganalisa data virtual secara signifikan.

Universitas Majalengka merupakan salah satu Perguruan tinggi Swasta terbesar di Wilayah III Cirebon ini berdiri sejak tahun 2006, total keseluruhan Fakultas yang ada di Universitas Majalengka ada 7 Fakultas Strata 1 dan 1 program Pasca Sarjana dengan memiliki 23 Program Studi yang masing-masing memiliki akreditasi B.

Media pengenalan kampus di Universitas Majalengka sudah menggunakan Video Profil. Tidak hanya itu terlihat juga dari beberapa baligho dan brosur yang tersebar di beberapa titik kota Majalengka. Daya tarik untuk para peminat Universitas Majalengka belum optimal dikarenakan informasi mengenai beberapa fasilitas sarana dan prasana yang dimiliki belum tervisualkan dengan detail yang terdapat di Universitas Majalengka kurang tergambarkan dengan jelas untuk para calon mahasiswa baru maupun masyarakat Majalengka. Maka dibutuhkan suatu media pengenalan kampus dengan memanfaatkan teknologi Virtual Reality bagi calon mahasiswa baru yang lebih menarik dan detail memberikan gambaran visualisasi nyata mengenai fasilitas-fasilitas yang terdapat dalam kampus. 


\subsection{Tinjuan Pustaka}

\section{A. RANCANG BANGUN}

Rancang merupakan serangkaian prosedur untuk menerjemahkan hasil analisa dari sebuah sistem dari sebuah sistem ke dalam bahasa pemrograman untuk mendeskripsikan dengan detail bagaimana komponen-komponen sistem di implementasikan. Rancang sistem adalah penentuan proses dan data yang diperlukan oleh sistem baru. Perancangan adalah kegiatan yang memiliki tujuan untuk mendesain sistem baru yang dapat menyelesaikan masalahmasalah yang dihadapi perusahaan yang diperoleh dari pemilihan alternatif sistem yang terbaik. Sedangkan pengertian bangun atau pembangunan sistem adalah kegiatan menciptakan sistem baru maupun mengganti atau memperbaiki sistem yang telah ada baik secara keseluruhan maupun sebagian. Bangun sistem adalah membangun sistem informasi dari komponen yang didasarkan pada spesifikasi desain. (Azizah, NU., 2014).

\section{B. BIDANG EKONOMI (PROMOSI} BARANG PAJANGAN/DISPLAY)

Kegunaan dan manfaat dari VR adalah untuk mempromosikan barang display atau pajangan. Salah satu toko yang telah menerapkan cara ini adalah toko Selfridges di jalan Oxford di London. Virtual Reality yang dimilikinya, pengunjung yang datang bisa mencoba beberapa produk yang dijual oleh toko dengan lebih nyata. Seperti produk jam tangan virtual 3D yang bisa dicoba dengan berdiri di depan layar. Saat itu kamera akan merekam penampilan dan gerakan calon pembeli. Calon pembeli pun bisa memilih dan mencoba dan merasakan sensasi menggunakan jam tangan virtual yang dijual. (Irwan, Asep. 2019).

C. TEKNOLOGI VIRTUAL REALITY

Virtual reality (VR) adalah salah satu aplikasi dari teknologi multimedia memiliki kelebihan dalam mendeskripsikan sebuah keadaan atau sebuah objek dimana visualisasi yang ditampilkan tidak hanya dapat dilihat dari satu sudut pandang saja namun dapat dilihat dari segala sudut, karena memiliki 3 dimensi visual sehingga pengguna dapat berinteraksi dengan suatu lingkungan yang disimulasikan oleh komputer (Virtual Environment).

(Trieddiantoro, P. H. 2015)

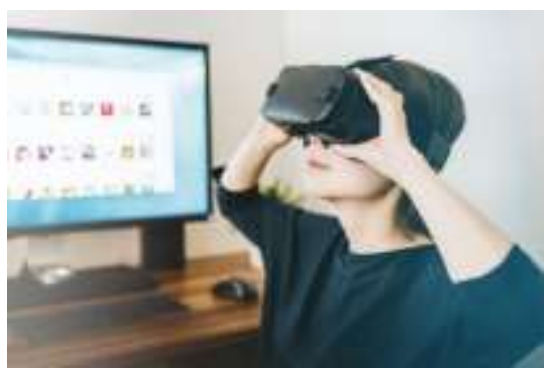

Gambar 1. Teknologi Virtual Reality

(Sumber : unsplash.com)

Virtual Reality (VR). Secara bahasa berarti keadaan nyata/ide yang "dimasukkan" ke dalam dunia maya atau memvirtualkan objek nyata/ide yang tetap memperhitungakan sifatsifat fisikanya. Oleh karena itu harus dibedakan dengan animasi 3D, yang terdapat pada film dan game, karena tidak memperhitungkan data dan kondisi fisik dari objek-objek yang berada di dalamnya (lingkungan virtual). Sebuah VR pasti memperhitungkan aspek ergonomis dan antropometri. Ini adalah added value sebuah VR. Ergonomis berarti barang yang divirtualkan harus cocok dengan anatomi tubuh manusia ketika digunakan seperti kita menggunakan barang-barang yang biasa berada di sekitar kita, sedangkan antopometri berarti di dalam virtualisasi tersebut diperhitungkan ukuran fisik dari gerakan manusia terhadap semua objek virtual di sekelilingnya. Dua hal tersebut merupakan aspek analisis yang menjadi pembeda VR terhadap games, aspek lainnya adalah fungsionalitas. Di sisi ini komponennya adalah reachability, touchability, dan accessability. Reachability berarti objek di dalam dunia vitual dapat dijangkau, dipegang, dapat berinteraksi dengan user. Secara sederhana, Virtual Reality adalah pemunculan gambar-gambar tiga dimensi yang di bangkitkan komputer, yang terlihat nyata dengan bantuan sejumlah peralatan tertentu. Ciri terpentingnya adalah dengan menggunakan perangkat yang dirancang untuk tujuan tertentu, teknologi ini mampu menjadikan orang yang merasakan dunia maya tersebut terkecoh dan yakin bahwa yang dialaminya adalah nyata.

\section{SEJARAH VIRTUAL REALITY}

Pada tahun 1966, Ivan Sutherland menemukan Head Mounted Display yang merupakan jendela ke dunia virtual. Seorang ilmuwan bernama Myron Krueger (1975) menemukan 
Videoplace yang memungkinkan penggunanya dapat berinteraksi dengan objek virtual untuk pertama kalinya. Jaron Lanier (1989) memperkenalkan Virtual Reality dan menciptakan bisnis komersial pertama kali di dunia maya. LB Rosenberg (1992) mengembangkan Augmented Reality untuk melakukan perbaikan pada pesawat boeing dan mengembangkan salah satu fungsi sistem AR yang disebut Virtual Fixtures, yang digunakan di Angkatan Udara AS Armstrong Labs dan menunjukan manfaatnya pada manusia. Steven Feiner, Blair Maclntyre dan dorée Seligmann (1992) memperkenalkan untuk pertama kalinya Major Paper untuk perkembangan Prototype AR. Hirokazu Kato (1999) mengembangkan ArToolkit di HITLab dan didemonstrasikan di SIGGRAPH. Bruce.

H Thomas (2000) mengembangkan ARQuake sebuah Mobile Game AR yang ditunjukan di International Symposium on Wearable Computers. Pada tahun 2008 Wikitude AR Travel Guide, memperkenalkan Android G1 Telephone yang berteknologi AR. Saqoosha (2009) memperkenalkan FLARToolkit yang merupakan perkembangan dari ArToolkit. FLARToolkit memungkinkan kita memasang teknologi AR di sebuah website, karena output yang dihasilkan berbentuk Flash. Wikitude Drive (2009) meluncurkan sistem navigasi berteknologi AR di Platform Android. Tahun 2010 Acrossair menggunakan teknologi AR pada I-Phone 3GS. (Trieddiantoro, P. H. 2015)

E. ELEMENT VIRTUAL REALITY

Sherman dalam Mihelj et al mengatakan bahwa ada 4 elemen dasar dari virtual reality, yaitu : Sherman WR, Craig AB (2003)

\section{Virtual Environment}

Definisi dari VR dan VE terus berkembang dan pada saat ini istilah keduanya saling berkaitan. Wilson \& D'Cruz (2006) mengatakan bahwa VR mengarah kepada teknik atau sistem berupa perangkat dan software, sedangkan VE merupakan lingkungan yang diciptakan melalui komputer. Stanney K (2001) "A computer-generated virtual environment presents descriptions of objects within the simulation and the rules as well as relationships that govern these objects" Virtual Environment adalah lingkungan yang disimulasikan oleh komputer, berupa lingkungan sebenarnya yang ditiru atau lingkungan yang hanya ada dalam imaginasi. Mihelj et al (2014)

\section{Virtual Presence}

Virtual Presence, yaitu sebuah perasaan keberadaan seseorang dari lingkungan virtual. Pengguna tersebut bereaksi dengan objek virtual selayaknya berinteraksi dengan objek nyata. Pengguna merepresentasikan perasaan dari berada di sebuah lingkungan virtual.

Waterworth JA, Waterworth EL (2003) "Virtual presence is very difficult to evoke with other media, as they do not offer actual sensory and physical immersion into the environment. The notion of absence has even been advanced as a concept analogous to presence, but evoked by other media" Waterworth mengatakan bahwa virtual presence sulit untuk dimunculkan melalui media selain VR karena media lain tersebut tidak memberikan fasilitas atau kemampuan kepada sensor aktual dan imersi fisik langsung terhadap lingkungan. Pemahaman dari kehadiran langsung telah ditingkatkan melalui konsep dari kehadiran yang dimunculkan melalui media. Schuemie, MJ, van der Straaten P, Krijn M, van der Mast CAPG (2001) “ In Immersion, a user is surrounded by the environment in a way that ensures a sense of presence or the feeling seen really in the depicted world"

Imersi merupakan keadaan dimana pengguna berada di sebuah lingkungan yang berupaya untuk meningkatkan perasaan ruang atau perasaan seperti berada di keadaan nyata. Virtual presence dapat dikategorikan menjadi physical (sensory) dan mental presence.

\section{a. Physical (sensory) Virtual Presence}

Kehadiran virtual secara fisik mendefinisikan virtual reality dan sekaligus membedakannya dari media lain. Kehadiran virtual secara fisik ini didapat dari memberikan pengguna sebuah lingkungan virtual dengan satu atau lebih sensor yang dapat merubah posisi pengguna dan gerakannya. Pada umumnya sistem virtual reality melakukan render lingkungan virtual melalui penglihatan, pendengaran, dan sentuhan.

\section{b. Mental Virtual Presence}

Tingkatan kemampuan kehadiran virtual secara mental tergantung pada tujuan yang ingin dicapai melalui virtual reality. Jika virtual reality digunakan dengan tujuan hiburan, maka diperlukan kehadiran virtual secara mental 
dengan tingkat tinggi. Bagaimanapun, kehadiran virtual secara mental kadang tidak begitu dibutuhkan. Tidak adanya kehadiran virtual secara mental tidak mendiskualifikasi media dari menjadi virtual reality.

\section{c. Sensory Feedback}

Umpan balik sensoris merupakan komponen krusial dari VR. Sistem VR memberikan umpan balik sensoris secara langsung melalui informasi visual. Sistem virtual reality memberikan umpan balik sensoris secara langsung kepada pengguna berdasarkan lokasi fisiknya.

\section{Interactivity}

William, Rice, dan Rogers (1988) mendefinisikan interaktivitas sebagai tingkatan dimana pada proses komunikasi para partisipan memiliki kontrol terhadap peran dan dapat bertukar peran dalam dialog mutual mereka. Satu penelitian yang dilakukan oleh McMillan dan Downes (1998) mengidentifikasi bahwa ada 6 dimensi interaktivitas, yaitu:

a. persuasi - menginformasikan;

b. kontrol lemah - kontrol tinggi;

c. aktivitas rendah - aktivitas tinggi;

d. satu arah - dua arah;

e. waktu tertentu - waktu fleksibel;

f. kesadaran rendah terhadap tempat kesadaran tinggi terhadap tempat;

William, Rice dan Rogers dalam Jancowski dan Hanssen (1996, p. 61) mendefinisikan interaktivitas sebagai derajat di mana partisipan dalam proses komunikasi memiliki kontrol, dan dapat bertukar peran dalam mutual discourse. Dengan menggunakan konsep mutual discourse, pertukaran, kontrol dan partisipan tersebut dapat dibedakan tiga level interaktivitas, yaitu:

a. Percakapan tatap muka dengan derajat interaktvitas tertinggi; (user to user)

b. Interaktivitas yang dimungkinkan antara orang dengan medium, atau orang dengan sistem di mana isi dapat dimanipulasi (misalnya videotex); (user to system)

c. Interaktivitas yang diperoleh dalam sistem informasi yang tak memungkinkan adanya intervensi dari pengguna untuk merubah konten (misalnya teletext). (user to document) (Trieddiantoro, P, H. 2015)

\section{F. VIRTUAL TOUR}

Virtual tour merupakan teknologi yang menempatkan user di dalam gambar dan memungkinkan user untuk meningkatkan kesadaran situasional serta meningkatkan daya lihat, tangkap dan menganalisa data virtual secara signifikan. Virtual tour sendiri biasanya digunakan untuk memberi pengalaman 'pernah berada' di suatu tempat hanya dengan melihat layar monitor. Penyajian virtual tour dapat dilakukan dengan cara memanfaatkan gambar, foto ataupun video, selain itu juga dapat menggunakan model 3 dimensi. (F Bailly, B McClendon, 2011.)

G. MODEL VIDEO PANORAMA $360^{\circ}$

Menurut Johan Felisitas dalam situs (http://www.ilmugrafis.com) panorama adalah gambar yang melukiskan pandangan umum atau secara luas tentang sebagian wilayah, pemandangan dari bentangan alam atau bangunan maupun object lainnya. Panorama memberikan efisiensi karena berisi bagian demi bagian pada suatu object dan menggabungkannya menjadi satu gulungan memanjang. Foto panorama $360^{\circ}$ adalah foto yang bisa dilihat atas, bawah, kiri, kanan, depan, dan, belakang kelihatan seperti apa yang fotografer lihat. Pengamat dapat merasakan pengalaman unik dengan ke segala arah. Menurut FR Daud secara umum jenis proyeksi foto panorama dapat dibagi dalam tiga bagian sebagai berikut:

1. Panorama datar (flat/plane) satu foto atau gabungan beberapa foto yang diambil dengan sudut pandang terbatas dan diproyeksikan dalam bentuk datar.

2. Panorama silinder (cylindrical) gabungan beberapa foto yang diambil 
berputar $360^{\circ}$ dari kiri ke kanan atau sebaliknya dan diproyeksikan dalam bentuk silinder.

3. Panorama bola (spherical) foto yang diambil tidak hanya berputar $360^{\circ}$ dari kiri ke kanan tapi juga $180^{\circ}$ ke atas dan bawah. Diproyeksikan dalam bentuk sebuah bola, kita sebagai pengamat berada di dalamnya. (Sumber: FR Daud, V Tulenan, XBN Najoan. 2016)

\section{H. GOOGLE CARDBOARD}

Google Cardboard adalah alat yang memberikan pengalaman Virtual Reality, dengan bantuan smartphone yang mendukung, aplikasi stereoscopic, dan dibantu lensa khusus, membuat semua orang dapat mencoba pengalaman 3D Experience Virtual Reality. Google Cardboard merupakan penemuan Google yang diumumkan pada saat acara Google I/O di California, 2014 lalu. (Sumber: FR Daud, V Tulenan, XBN Najoan. 2016)

Google Cardboard merupakan alat virtual reality yang menggunakan smartphone sebagai platform/layar. Google Cardboard ditujukan agar pengguna smartphones dapat merasakan Virtual Reality dengan cara yang mudah dan murah. Kelebihannya, apabila Anda menggerakkan kepala Anda ke kiri atau ke kanan, maka Anda juga bisa melihat kondisi sekitar dari aplikasi/permainan tersebut seperti nyata. Google Cardboard dapat digunakan pada kebanyakan ponsel Android modern, termasuk Iphone juga bisa. Handphone harus menjalankan Android 4.1 (Jelly Bean) atau ke atas. Layar handphone yang lebih besar lebih baik yaitu antara 4.5" s/d 6". Ukuran layang yang ideal adalah 5.5" dengan resolusi Full HD, lebih baik lagi jika Quad HD. Contoh fungsinya antara lain:
1. Bermain game seakan-akan kita berada di dalam;
2. Menonton video 3D seperti di bioskop;
3. Menonton video $360^{\circ}$;
4. Keliling dunia dengan Google Earth.

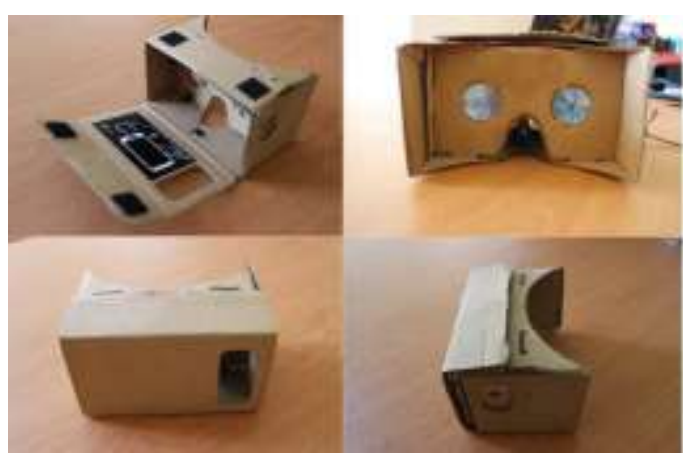

Gambar 2. Bagian Dalam Google Cardboard

(Sumber: FR Daud, V Tulenan, XBN Najoan. 2016)

\section{MULTIMEDIA}

Multimedia dalam konteks komputer menurut Hofstetter (2001) adalah penggunaan komputer untuk menyajikan dan menggabungkan teks, suara, gambar, animasi dan video dengan alat bantu (tool) dan koneksi (link) sehingga pengguna dapat melakukan navigasi, berinteraksi, berkarya dan berkomunikasi. Berdasarkan pengertian itu, multimedia terdiri dari empat faktor, yaitu: (i) ada komputer yang mengkoordinasikan apa yang dilihat dan didengar, (ii) ada link yang menghubungkan pengguna dengan informasi, (iii) ada alat navigasi yang membantu pengguna menjelajah jaringan informasi yang saling terhubung, dan (iv) multimedia menyediakan tempat kepada pengguna untuk mengumpulkan, memproses, dan mengkomunikasikan informasi dengan ide secara interaktif.

\section{PENGERTIAN MULTIMEDIA}

Multimedia berasal dari kata multi dan media. Multi berasal dari bahasa Latin, yaitu nouns yang berarti banyak atau bermacammacam. Sedangkan kata media berasal dari bahasa Latin, yaitu medium yang berarti perantara atau sesuatu yang dipakai untuk menghantarkan, menyampaikan, atau membawa sesuatu.

Kata medium dalam American Heritage Electronic Dictionary (1991) diartikan sebagai alat untuk mendistribusikan dan mempresentasikan informasi.

Berdasarkan itu multimedia merupakan perpaduan antara berbagai media (format file) yang berupa teks, gambar (vektor atau bitmap), grafik, sound, animasi, video, interaksi, dan lain-lain yang telah dikemas menjadi file digital (komputerisasi), digunakan untuk 
menyampaikan atau menghantarkan pesan kepada publik. (Hofstetter, 2001)

\section{ELEMENT MULTIMEDIA}

\section{INTERAKTIF}

Ada lima elemen atau teknologi utama dalam multimedia interaktif, yaitu, Teks, Grafik, Audio, Video, dan Animasi. Multimedia interaktif menggabungkan dan mensinergikan semua media yang terdiri dari teks, grafik, audio, video, dan interaktivitas Hofstetter (2001). Selain itu, interaktifitas juga merupakan bagian daripada elemen yang diperlukan untuk melengkapi proses komunikasi interaktif dalam penggunaan multimedia. Setiap elemen ini memiliki perannya masingmasing dalam mewujudkan suatu informasi yang menarik dan berkesan. Interaktivitas bukanlah medium. Interaktivitas adalah rancangan dibalik suatu program multimedia. Interaktivitas memungkinkan seseorang untuk mengakses berbagai macam bentuk media atau jalur di dalam program multimedia sehingga program tersebut lebih berarti dan lebih memberikan kepuasan bagi pengguna. Interaktivitas disebut juga sebagai interface design atau human factor design. Interaktivitas dapat dibagi menjadi dua macam struktur, yaitu struktur linear dan struktur nonlinear. Struktur linear menyediakan satu pilihan situasi saja kepada pengguna, sedangkan struktur nonlinear terdiri dari berbagai macam pilihan kepada pengguna. Hofstetter (2001). Green \& Brown (2002: 3) pun menjelaskan, terdapat beberapa metode yang digunakan dalam menyajikan multimedia, yaitu:

1. Berbasis kertas (Paper-based), contoh: buku, majalah, brosur;

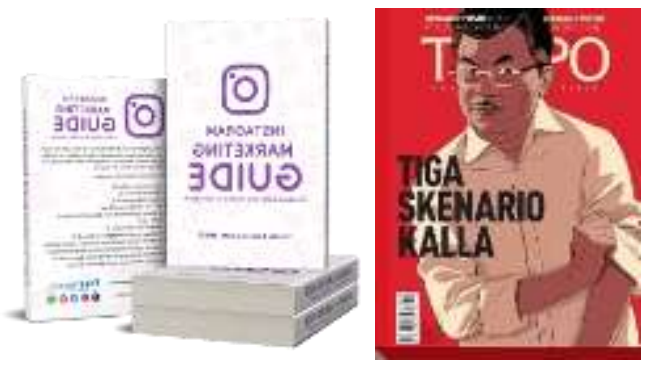

Gambar 3. Contoh Paper-Based

(Sumber : Majalah Tempo.com, freshtrendx.com)
2. Berbasis cahaya (Light-based), contoh: slide shows, transparasi;

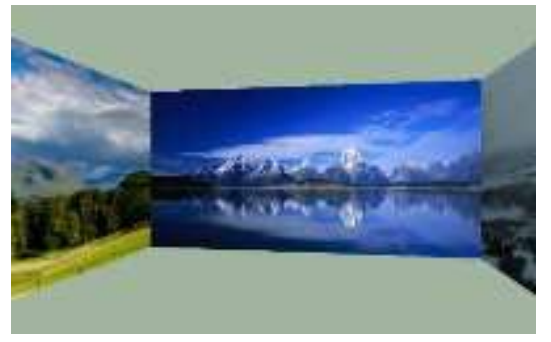

Gambar 4. Contoh Light-Based dalam Slide Show

(Sumber : .jqueryscript.net)

3. Berbasis suara (Audio-based), contoh: CD Players, tape recorder, radio;

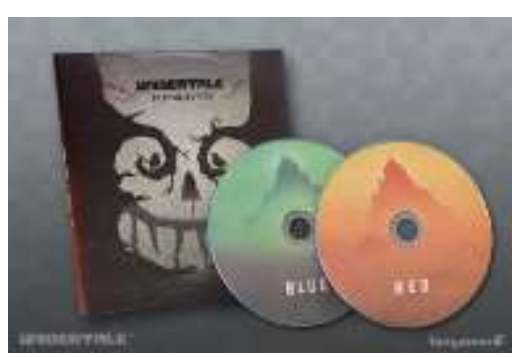

Gambar 5. Contoh CD Players

(Sumber :Fangamer.com)

4. Berbasis gambar bergerak (Moving-imagebased), contoh: televisi, VCR (Video cassette recorder), film;

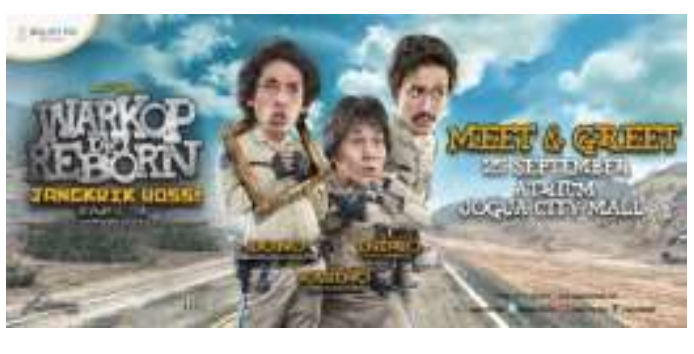

Gambar 6. Contoh Film

(Sumber : bioskoptoday.com) 
5. Berbasiskan digital (Digitally-based), contoh: komputer.

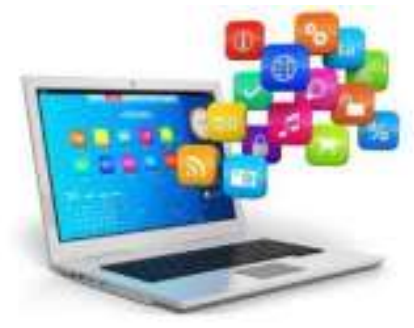

Gambar 7. Contoh Laptop

(Sumber : Liputan6.com)

Interaktivitas Sebagai Pusat Aplikasi Multimedia Adanya interaktivitas dan fitur interaktif dalam aplikasi multimedia telah menjembatani interaksi antara komputer dan pengguna. Kunci timbulnya interaktivitas yaitu adanya pemberdayaan pengguna dalam menggunakan aplikasi multimedia sehingga dapat mengontrol isi dan aliran informasi (Vaughan, 1998). Hal ini telah merangsang adanya perubahanperubahan penting dalam sistem pendidikan dan dampak cara penyampaikan informasi kepada peserta didik. Kemajuan teknologi multimedia yang berbasis web telah membantu perkembangan kemampuan untuk efektif memanfaatkan multimedia interaktif dalam proses pembelajaran.

\section{J. USABILITY}

Usability berasal dari kata usable yang berarti dapat digunakan dengan baik. Usability sendiri lebih tepat dikatagorikan sebagai paradigma dari sebuah aplikasi (baik dari sisi perangkat lunak maupun perangkat keras) yang menggambarkan tingkat kenyamanan pemakaiaan dari sisi pengguna. Definisi dari usability sendiri menurut ISO (inter nasional Standart Organization) adalah "effectiveness, efficiency and satisfaction with which a specified set of users can achieve a specified set of task in particular environment".

Kemudahan dan kenyamanan pengguna sendiri merupakan suatu hal yang relatif jika dibandingkan berdasarkan opini, karenanya dibutuhkan criteria dari ukuran kemudahan penggunaan yaitu (Golien, 2004) :

1. Mudah dipelajari : Dalam konsep yang lain dinyatakan bahwa sebuah system dianggap mudah dipelajari (Searman, 2005), jika seseorang pengguna kategori menengah dapat memahami desain hanyay dalam waktu kurang lebih sepuluh menit.

2. Mudah diingat : Dengan tampilan yang familiar dan sederhana akan sangat membantu pengguna untuk mudah mengingat komposisi desain.

3. Mudah dioperasikan : Sebuah system yang mudah dipelajari serta diingat, secara psikologis akan memberi kesan bahwa system mudah dioperasikan.

4. Mudah dieksplorasikan: Khusus bagi para pangguna yang dengan kategori mahir, mampu melakukan eksplorasi lebih lanjut dari system. Terutama untuk fasilitasfasilitas yang dianggap mampu mempercepat sistem.

5. Kepuasan pengguna: Meski kepuasan panggunana tidak memiliki ukuran yang baku, tetapi dapat diukur dari kemudahan dan kenyamanan pengguna dalam mencapai tujuan dari sistem yang dijalankan, misal : pengguna akan merasa puas setelah melakukan proses pencetakan yang hasilnya sama dengan yang diketik dari sebuah aplikasi word processor.

\section{K. PRINSIP USABILITY}

Sedangkan untuk mencapai sebuah tingkat usability yang baik bagi para pangguna, dibutuhkan tiga prinsip (Dix, 1993) yaitu :

1. Learnability

Seseorang pengguna pemula mampu mempelajari sistem dan memanfaatkan sistem secara optimal. Di dalam prinsip ini terbagi menjadi lima bagian yaitu :

a. Predictability

Pengguna mampu menentukan hasil dari sebuah tindakan didalam sistem. Contoh : jika terjadi klik tombol simpan maka pengguna dapat 
menebak bahwa hasil dari tindakan tersebut adalah menyimpan data.

b. Synthesizability

Pengguna dapat melihat hasil yang terjadi atau tanda sedang terjadinya suatu proses sesegera mungkin.

c. Familiarity

Melakukan analogi dalam desain sitem dengan aplikasi sejenis ataupun alat sejenis yang sebelumnya telah dianggap populer.

d. Generalizability

Membuat desain operasi sistem yang juga berlaku sama di aplikasi lain yang sejenis, contoh : operasi edit(cut/copy /paste).

e. Consistency

Konsisten dalam penggunaan berbagai istilah maupun ukuran.

2. Flexibility

Sebuah sistem yang dianggap memnuhi usability, diharapkan dapat dioperasikan dengan prosedur yang tidak kaku. Sebuah sistem yang dianggap memnuhi standar fleksibilitas jika memnuhi konsep sebagai berikut :

a. Dialogue Initiative

Pengguna memiliki kebebasan dalam sebuah kotak dialog, contoh : dalam kotak dialog penyimpanan dokumen, terdapat tombol untuk meneruskan proses dan sekaligus membatalkan.

b. Multi Threading

Pengguna dapat menjalankan aplikasi lain ataupun proses lain di saat sebuah proses lain di saat sebuah proses atau sistem sedang dijalankan.

c. Task Migrability

Kemempuan untuk melakukan migrasi, baik berupa data ataupun hasil proses ke aplikasi lain, contoh : hasil sebuah proses dapat diedit di aplikasi word processor.

a) Substitutivity

Sebuah perintah dapat diganti dengan padanan lain, contoh : penyediaan shortcut.

b) Costumizability

Desain dapat dimodifikasi oleh pengguna secara adaptif atau sesuai dengan tujuan utama masing-masing, contoh : pengaturan toolbar dan letak icon.

3. Robustness

Prinsip ini diartikan sebagai kehandalan sebuah sistem dalam mencapai tujuan khususnya dari sudut pandang pengguna . Dalam pencapaain, dibutuhkan empat kriteria yaitu :

a. Observability

Pengguna bisa melakukan observasi pendahuluan sebelum benar-benar melakukan proses yang sesungguhnya.

b. Recoverability

Kemampuan koreksi dari sistem jika pengguna melakukan kesalahan.

c. Responsiveness

Sebuah sistem yang responsif berarti mampu menerima tindakan user dengan stabil tanpa ada kendala yang timbul akibat komunikasi dari pengguna.

d. Task conformance

Kenyamanan pengguna dalam melakukan pekerjaan yang terdapat dalam sistem yang dianggap handal. 


\section{WARNA}

Warna adalah hasil dari cahaya yang terbentuk dari hue (corak), intensity (intensitas) dan saturation (kejenuhan atau jumlah putih pada warna). Seseorang yang mempunyai penglihatan warna normal mampu membedakan kira- kira 128 warna yang berbeda. Dengan warna manusia mampu membedakan satu objek dengan objek yang lain, sehingga manusia dapat terbantukan dalam mengolah data menjadi informasi.

Penggunaan warna yang sesuai dengan pengguna akan mempertinggi efektifitas tampilan grafis. Tetapi tidak ada standar yang dapat digunakan sebagai acuan resmi tentang penggunaan warna yang bagus, karena karakteristik orang per orang berbeda dalam hal persepsi tentang warna. (Asih, Y. 2009)

Beberapa aspek yang perlu diperhatikan dalam penggunaan warna antara lain :

\section{Aspek Psikologi}

a. Hindari penggunaan warna tajam secara simultan. Warna cyan, biru dan merah tidak dapat dilihat secara serempak, karena dapat menyebabkan mata menjadi lelah.

b. Hindari warna biru murni untuk teks, garis tipis dan bentuk yang sangat kecil. Mata kita tidak dapat melihat objek yang terperinci/kecil, tajam serta bergelombang pendek.

c. Hindari warna merah dan hijau untuk tampilan yang berskala besar, tetapi gunakan warna biru dan kuning

d. Pengaturan cahaya di dalam ruangan diperlukan karena warna akan berubah ketika cahaya berubah.

e. Kombinasi warna terjelek dan terbaik ditunjukkan seperti tabel berikut :
Tabel 1. Kombinasi Warna Buruk Saat Digunakan untuk Design

\begin{tabular}{|c|c|c|}
\hline $\begin{array}{l}\text { Latar } \\
\text { Belakang }\end{array}$ & Garis Tipis dan Teks & Garis Tebal dan Teks \\
\hline Putilh & Kuning( $\left(100^{A}\right.$ ), Cyra(94:6) & Kuning(94\%) C $\mathrm{Cru}\left(75^{\circ} \%\right)$ \\
\hline Hiram & 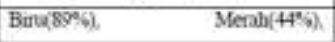 & Bing(1\%). Mageata(31\%) \\
\hline & Mapertia (23\%) & \\
\hline Menh & 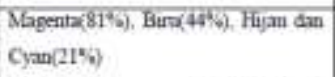 & Buru(8iS),Magenta(31\%) \\
\hline Hegali & 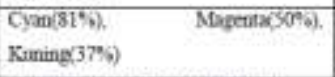 & $\begin{array}{l}\text { Cras(81\%). Magetia \& } \\
\text { Kreing(44\%) }\end{array}$ \\
\hline Bina & 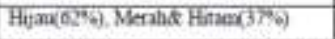 & Hejal (HWe, Merahs Hitam(Jis) \\
\hline Cyan & $\begin{array}{l}\text { Fitum }(315) \quad \text { Kuning(75\%) } \\
\operatorname{Prtil}(31 \%)\end{array}$ & $\begin{array}{l}\text { Kuning } 6 \% \%) \quad \text { Hijar }(025), \\
\text { Pural(56\%) }\end{array}$ \\
\hline Magmia & 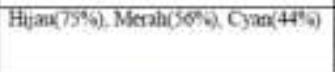 & $\begin{array}{l}\text { Cyre(81\%) } \quad \text { Hi;nu(69\%) } \\
\text { Merala(45) }\end{array}$ \\
\hline Kining & Rath dan Cyan (8I\%) & $\begin{array}{l}\text { Punzori\%). Cyzu(S6\%) Higu } \\
\text { (25\%) }\end{array}$ \\
\hline
\end{tabular}

Tabel 2. Kombinasi Warna Terbaik

\begin{tabular}{|c|c|c|}
\hline $\begin{array}{l}\text { Latar } \\
\text { Belakang }\end{array}$ & Garis Tipis dan Teks & Garis Tehal dan Teks \\
\hline Paill & $\begin{array}{l}\text { Buv(94\%), Hitam }\left(63^{\circ}\right) \text {. } \\
\text { Merah(25\%) }\end{array}$ & Hitam(69\%) Bent(63\%), Merally31\%) \\
\hline Hitan & Prithing5\%, Kunimg(095) & 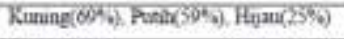 \\
\hline Menah & $\begin{array}{l}\text { Koning(75\%) Panb }(56 \%) \text {. } \\
\text { Hitan( }(44 \%)\end{array}$ & $\begin{array}{l}\text { Hutam(3O5) Kiming } 46 \%) \text {. } \\
\text { Putih(44\%), Cran(31\%) }\end{array}$ \\
\hline Hijas & $\begin{array}{l}\text { Fitum(1005) } \\
\text { Merab(25\%) }\end{array}$ & 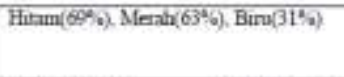 \\
\hline Berve & $\begin{array}{l}\text { Pantic(81\%) Kanine(5\%क). } \\
\text { Cyan(25\%) }\end{array}$ & 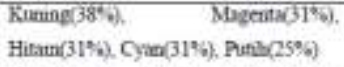 \\
\hline Cyan & $\begin{array}{l}\text { Benawow) } \\
\text { Merah(3T\%) }\end{array}$ & 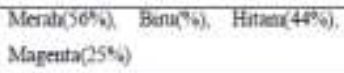 \\
\hline Magenta & $\begin{array}{l}\text { Hixm(635) } \\
\text { Bura(4686) }\end{array}$ & 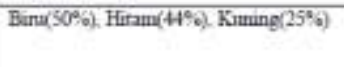 \\
\hline Kuning & $\begin{array}{l}\text { Merah }(63 \%) \\
\text { Hitam(56\%) }\end{array}$ & $\operatorname{Menhi}(75 \%)$, Bam(63\%), Hitan(50\%) \\
\hline
\end{tabular}

1. Aspek Persepsi

Layar tampilan dapat dterima atau tidak oleh pengguna sangat bergantung pada warna yang digunakan. Warna dapat meningkatkan interaksi hanya jika implementasinya mengikuti prinsip dasar dari penglihatan warna oleh manusia. Tidak semua warna ini dapat dibaca. Secara umum latar belakang dengan warna gelap akan memberikan kenampakan yang lebih baik (informasi lebih jelas) dibanding warna yang lebih cerah.

2. Aspek Kognitif

Penggunaan warna bertujuan untuk menarik perhatian atau pengelompokan informasi, 
sehingga tidak perlu menggunakan warna yang berlebihan.

\subsection{Metodologi Penelitian}

Kerangka Penelitian

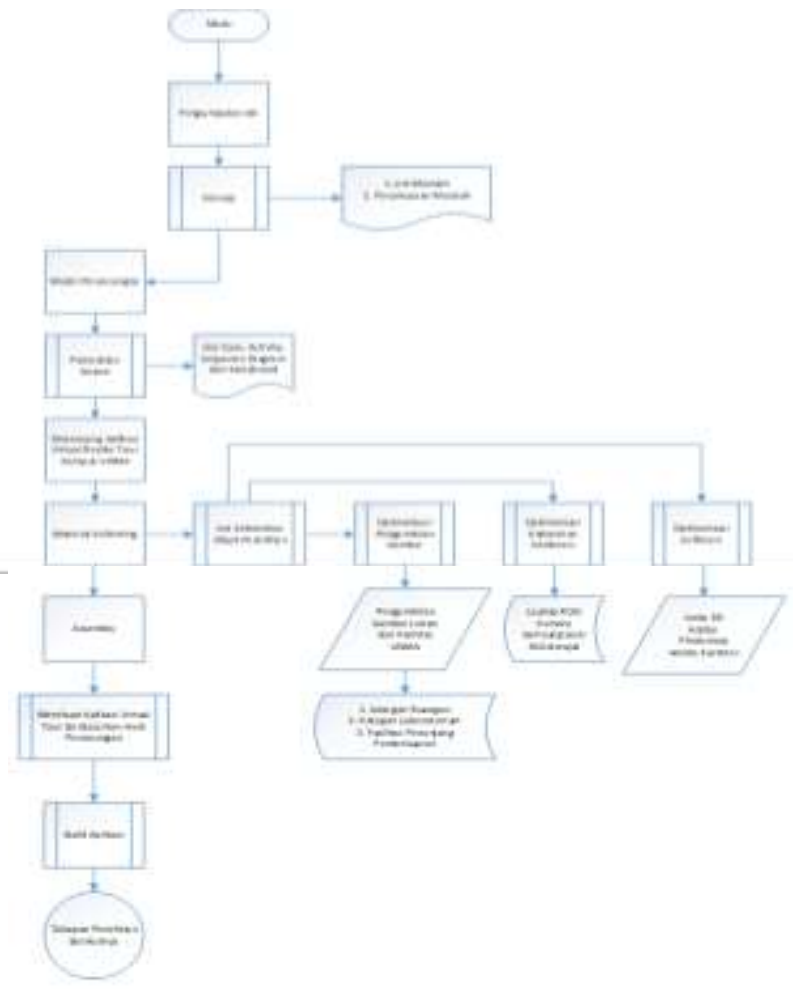

Gambar 8. Kerangka Penelitian

\section{PEMBAHASAN}

\subsection{ANALISIS SISTEM YANG DIUSULKAN}

Pada tahap perancangan ini dibuatkan alur sistem aplikasi virtual tour Kampus Universitas Majalengka yang menggambarkan akses yang dilakukan user, secara umum alur sistem pengenalan Kampus Universitas Majalengka yang dibuat setelah adanya aplikasi virtual tour ini adalah sebagai berikut :

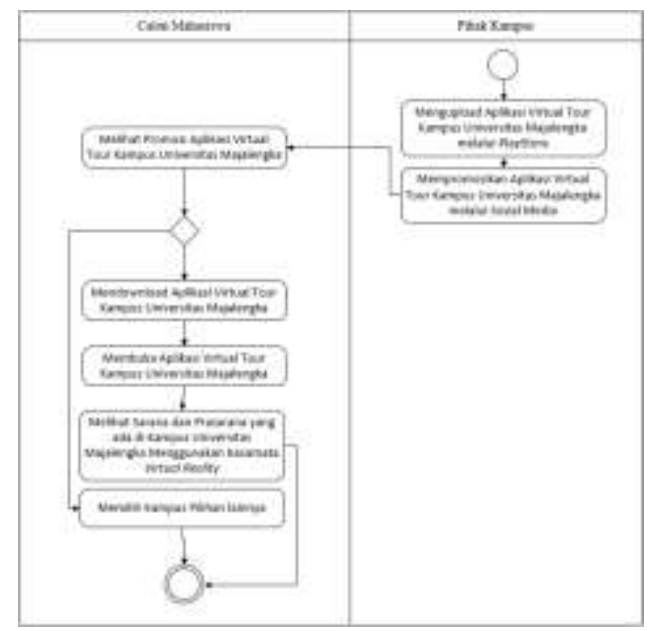

Gambar 9. Analisis Usulan
Dalam perancangan aplikasi virtual tour Kampus Universitas Majalengka dibuatkan diagram use case, dimana diagram use case ini menjelaskan atau menerangkan perilaku yang diinginkan oleh pengguna. Pada aplikasi virtual tour kampus Universitas Majalengka ini user dapat memilih menu seperti, menu tampilan ruangan, menu tampilan laboratorium, menu tampilan lainnya, menu Tutorial, keluar. Use case diagram pada penelitian ini dapat dilihat pada gambar 10.

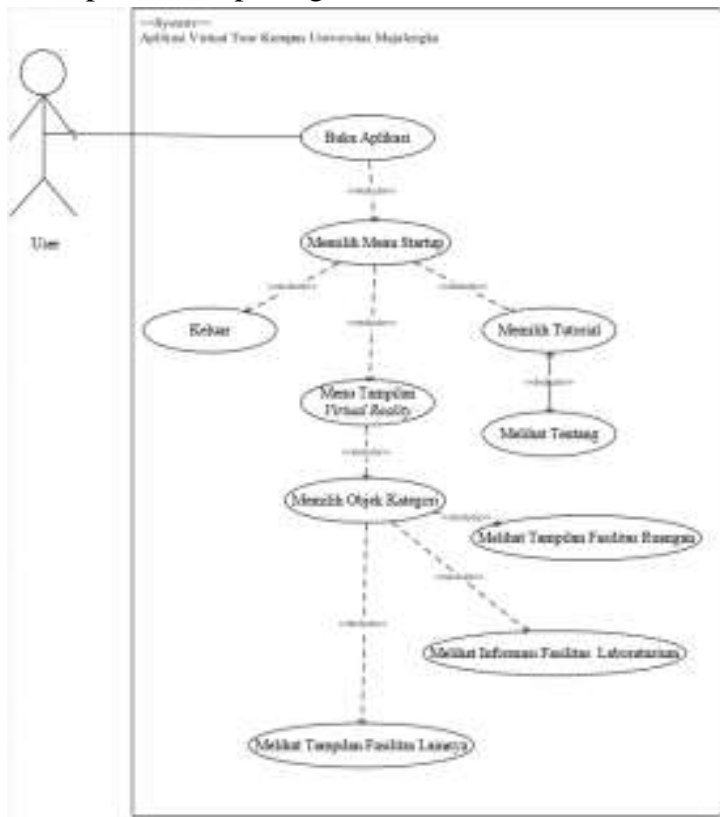

Gambar 10. Use Case Diagram Aplikasi Virtual Tour Kampus Universitas Majalengka

Perancangan activity diagram ini untuk menjelaskan alur aktivitas dalam sistem yang dirancang yang melibatkan tindakan yang dilakukan pengguna atau user dalam menggunakan aplikasi, pada gambar dibawah berikut adalah activity diagram yang menjelaskan atau menggambarkan tindakan pengguna dalam menjalankan aplikasi saat menampilkan sarana dan prasarana dan infonya.

Activity Diagram adalah diagram yang menggambarkan workflow (Aliran Kerja) atau aktivitas dari sebuah sistem atau proses. Activity Diagram Menu Tampilan Virtual Reality Menggunakan Kacamata Google Cardboard dapat dilihat pada gambar 11 dibawah ini. 


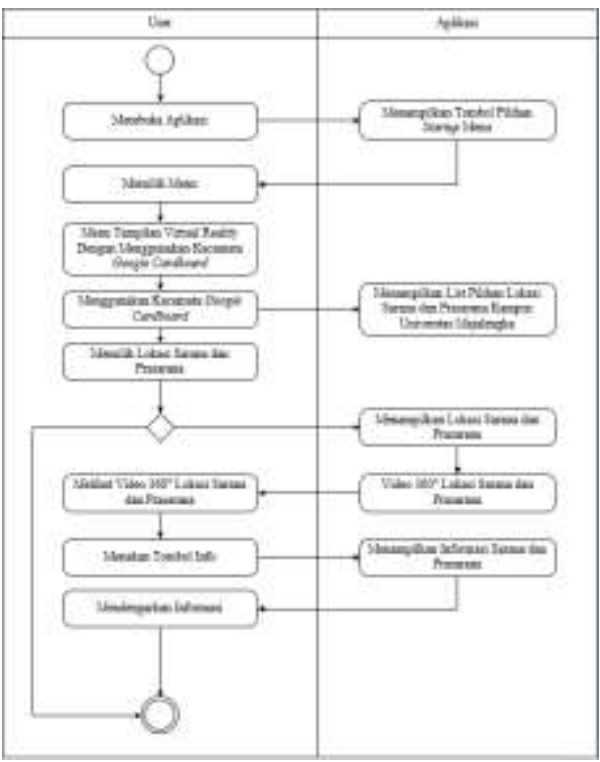

Gambar 11. Activity Diagram Menu Tampilan Virtual Reality Menggunakan Kacamata Google Cardboard

\subsection{PERANCANGAN SISTEM 1. STORYBOARD}

Dalam perancangan aplikasi virtual tour Kampus Universitas Majalengka ini menggunakan storyboard agar memperjelas alur perancangan aplikasi tersebut. Berikut adalah perancangan storyboard yang telas dibuat :

a. Perancangan Storyboard

Pada perancangan storyboard ini dibuat untuk menggambarkan kepada pengguna dalam perubahan alur aplikasi sehingga pengguna dapat mengetahui secara jelas alur yang terdapat pada aplikasi virtual tour Kampus Universitas Majalengka tersebut secara jelas. Dibawah ini adalah storyboard yang dibuat.

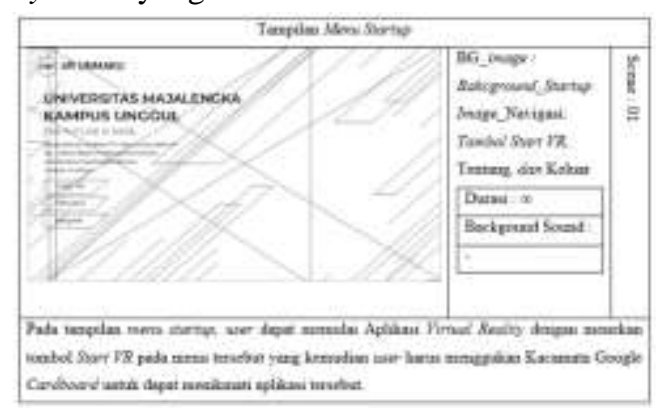

Gambar 12. Story Board Menu Startup

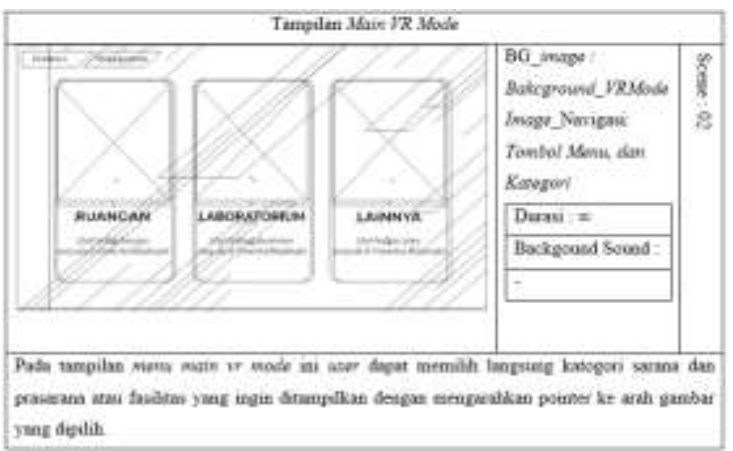

Gambar 13. Story Board Main VR

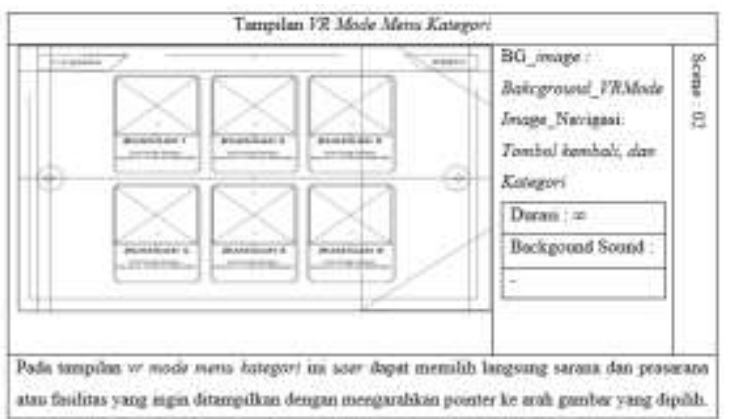

Gambar 14. Story Board VR Mode

\section{HASIL DAN PEMBAHASAN}

\section{a. Hasil Perancangan}

Pada tampilan interface ini peneliti menggunakan software Adobe Photoshop CC 2019 untuk mendesain tampilan interface mulai dari background, splash screen, button-button dan aplikasi virtual tour Kampus Universitas Majalengka tersebut. Berikut adalah tampilan interface aplikasi :

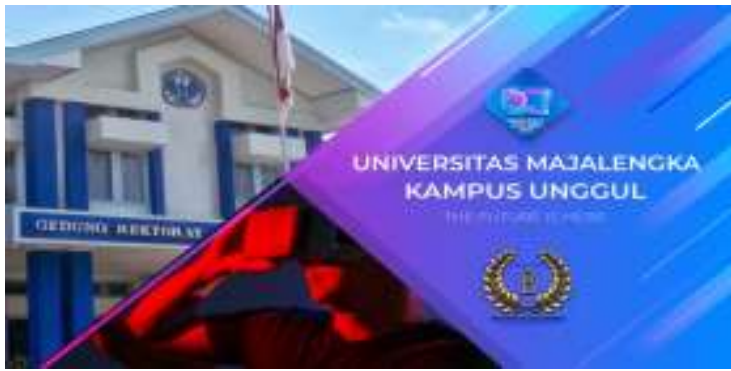

Gambar 15. Tampilan background image aplikasi pada tampilan splash screen

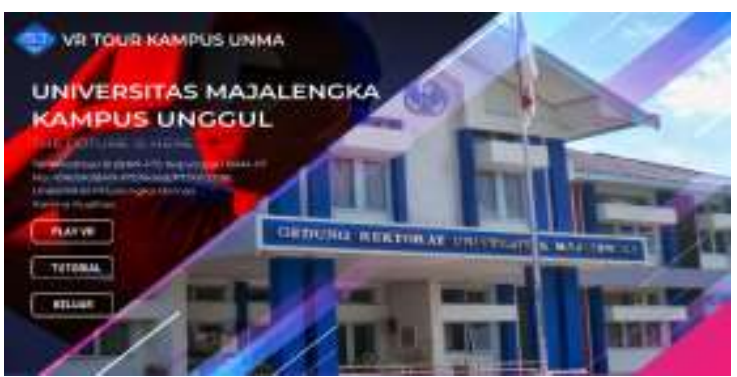


Gambar 16. Tampilan background image aplikasi pada tampilan menu startup

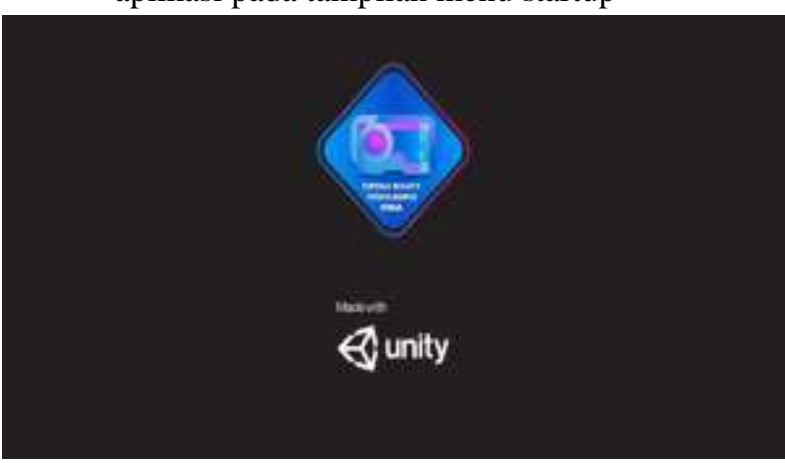

Gambar 17. Tampilan Loading screen aplikasi pada tampilan menu VR Mode

Pada aplikasi virtual tour Kampus Universitas Majalengka ini, peneliti menggunakan software Unity versi 5.6 untuk pembuatan aplikasi virtual tour Kampus Universitas Majalengka yang menggunakan perangkat Android dan untuk pengambilan photo dan video $360^{\circ}$ sendiri peneliti menggunakan perangkat kamera Samsung Gear $360^{\circ}$, karena proses pengambilan photo dan video sarana dan prasarana dapat dilakukan dengan cepat dan tanpa proses editing untuk proses penggabungan photo-photo tersebut.

Pada perancangan splash screen, dimasukannya bahan-bahan seperti image background dan logo serta image kampus universitas majalengka yang akan ditampilkan pada tampilan awal aplikasi dijalankan oleh user.

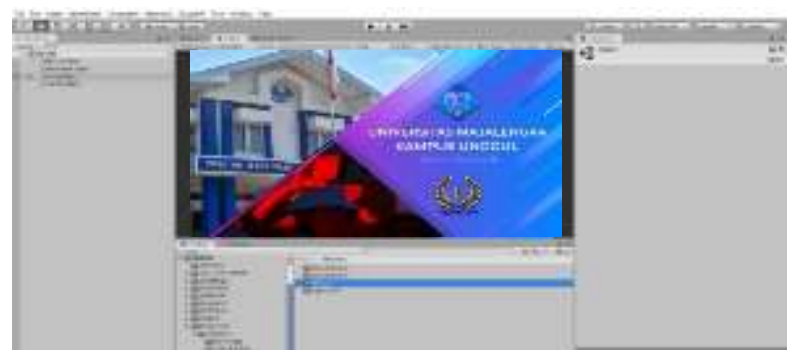

Gambar 18. Perancangan tampilan splash screen

Perancangan tampilan menu setup dibuat untuk pemilihan mode dalam aplikasi, pada perancangan ini dimasukan bahan-bahan image button yang di buat semenarik mungkin agar user dapat dengan mudah menggunakan dan memahami penggunaan aplikasi virtual tour Kampus Universitas Majalengka ini.

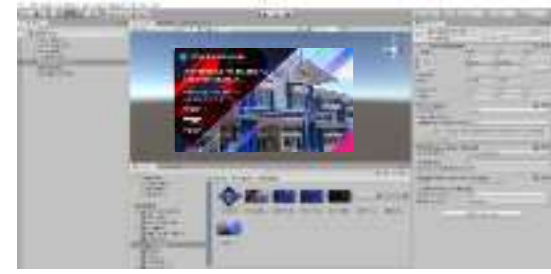

Gambar 19. Perancangan tampilan menu setup

Pada perancangan menu VR mode ini dibuat agar memudahkan user untuk melakukan perpindahan sarana dan prasarana yang ada di kampus Universitas Majalengka sebelumnya ke sarana dan prasana selanjutnya tanpa harus keluar dari aplikasi.

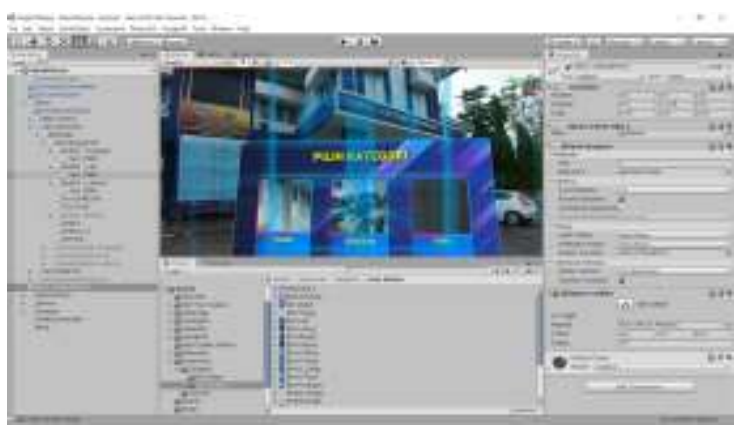

Gambar 20. Perancangan tampilan Menu VR Mode

\section{b. Pengujian Usability}

Pengujian usability dilakukan untuk mengetahui tanggapan pengguna ketika menggunakan aplikasi virtual tour Kampus Universitas Majalengka. Pengujian ini diberikan kepada Mahasiswa dan Masyarakat Umum.

a) Hasil

Angket diberikan kepada Mahasiswa dan Masyarakat Umum yang bertujuan untuk mengetahui tanggapan Mahasiswa dan Masyarakat Umum terhadap aplikasi virtual tour Kampus Universitas Majalengka. Angket ini terdiri dari 10 buah pernyataan dengan 4 kategori skor tanggapan. Kategori skornya yaitu Sangat Setuju (SS) dengan skor 4, Setuju (S) dengan skor 3, Kurang Setuju (KS) 
dengan skor 2 dan Tidak Setuju (TS) dengan skor 1. Angket ini diberikan kepada 30 orang baik Masyarakat Umum atau Mahasiswa Universitas Majalengka. Hasil rekapitulasi tanggapan tersebut disajikan pada Lampiran.

Untuk mengetahui tanggapan Mahasiswa dan Masyarakat Umum terhadap aplikasi virtual tour Kampus Universitas Majalengka dapat dilihat pada Tabel 3.

Tabel 3. Rekapitulasi analisis hasil angket tanggapan Mahasiswa dan Masyarakat Umum untuk setiap pernyataan

\begin{tabular}{|c|c|c|c|}
\hline No. & Perayataan & $\begin{array}{c}\text { Skar } \\
\text { Rata-rata }\end{array}$ & $\begin{array}{c}\text { Perientaue Capaian } \\
\text { Sker terthadap Sher } \\
\text { Malsimal (\%) }\end{array}$ \\
\hline 1. & $\begin{array}{l}\text { Samt pertama kati mencobs rolikasi mudah } \\
\text { degunakm. }\end{array}$ & 330 & $5250^{\circ}$ \\
\hline 2. & $\begin{array}{l}\text { Simbol-aimbol dalam aplikasi mudah } \\
\text { dicenali dipahami. }\end{array}$ & 3.40 & 85.000 : \\
\hline 3. & Teka debrai aplikani mubih diboce. & 321 & 51.6736 \\
\hline 4 & Mudah mentmi tembof yose ung butuhksin. & 323 & 00.8396 \\
\hline 5 & 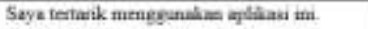 & 3.63 & $90.85 \%$ \\
\hline 6 & 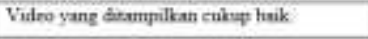 & 330 & 825096 \\
\hline 7. & $\begin{array}{l}\text { Gemburan Sarnan don Prasenea yara } \\
\text { diampilkan cukop jelas. }\end{array}$ & 3.43 & $85.83 \% 6$ \\
\hline$=$ & 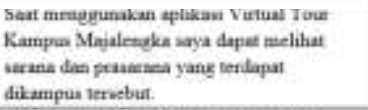 & 3.47 & $8667 \%$ \\
\hline 9. & $\begin{array}{l}\text { Dessin penilhath wama poda tumpilas } \\
\text { cukup haik. }\end{array}$ & 3.30 & $82.50 \%$ \\
\hline 10. & 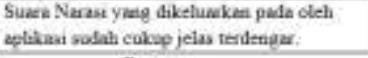 & 290 & $\pi 250 \%$ \\
\hline \multicolumn{2}{|r|}{ Rata-rata } & 332 & $83.08 \%$ \\
\hline
\end{tabular}

DIAGRAM REKAP HASIL PENDAPAT KUISIONER

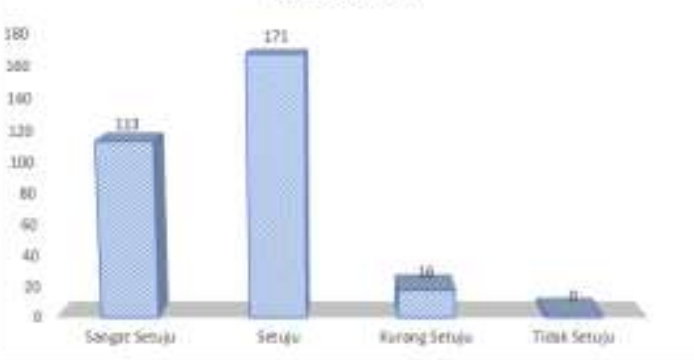

Gambar 21. Diagram Rekap Hasil Pendapat Kuisioner

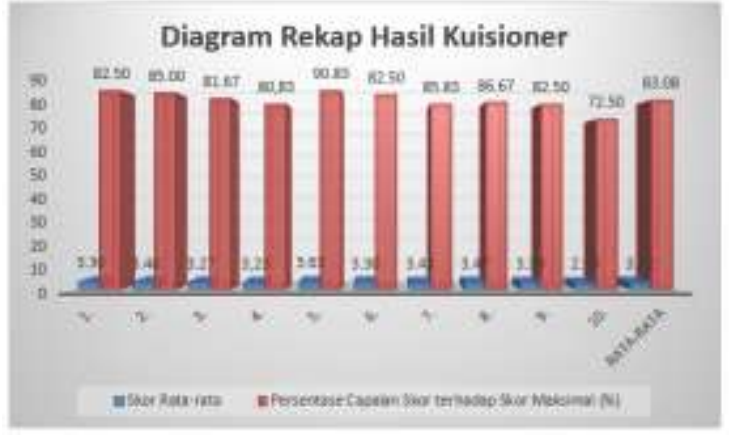

Gambar 22. Diagram Rekap Hasil Kuisioner

Berdasarkan data pada Tabel 3, sebesar 90.8\% mahasiswa dan masyarakat umum menyatakan tertarik menggunakan aplikasi virtual tour Kampus Universitas Majalengka. Sebesar $82.5 \%$ mahasiswa dan masyarakat umu menyatakan setuju bahwa aplikasi virtual tour Kampus Universitas Majalengka mudah digunakan. Dan sebesar $86,6 \%$ mahasiswa dan masyarakat umum menyatakat merasa berada di tempat dan dapat melihat sarana dan prasarana saat menggunakan aplikasi virtual tour Kampus Universitas Majalengka.

\section{KESIMPULAN}

A. Kesimpulan

Dari uraian yang terdapat pada penelitian ini, maka menarik beberapa kesimpulan sebagai berikut :

1. Aplikasi virtual tour Kampus Universitas Majalengka dirancang menggunakan software Unity versi 2019.2.6f1 dan SDK GoogleVRForUnity Versi 1.200.1 dengan menggunakan metode pengembangan sistem MDLC (Multimedia Development Life Circle) yang terdiri dari beberapa tahap yaitu concept, design, material collecting, assembly, testing dan distribution.

2. Model photo dan video di ambil menggunakan kamera khusus yaitu Samsung Gear 360, proses photo dan 
video menggunakan kamera ganda yang kemudian digabungkan oleh system pada kamera itu sendiri sehingga hasil output dari photo dan video sudah $360^{\circ}$, adaput proses editing yang dilakukan adalah proses pemotongan durasi video.

3. Dengan adanya aplikasi virtual tour Kampus Universitas Majalengka, pengenalan Kampus Universitas Majalengka kepada calon mahasiswa dan mahasiswi dapat dikenalkan secara lebih menarik juga menarik minat calon mahasiswa dan mahasiswi untuk dapat mengetahui secara lebih detail tetang fasilitas sarana dan prasarana yang ada di kampus Universitas Majalengka. Dengan hasil survei dengan kuesioner sebesar $90,8 \%$ masyarakat tertarik menggunakan aplikasi ini. Sebesar 86,6\% mahasiswa dan masyarakat umum saat menggunakan aplikasi VR Unmaku menyatakat merasa berada di tempat dan dapat melihat sarana dan prasarana. Dan persentase rata-rata keseluruhan sebesar $86,6 \%$.

\section{B. Saran}

Saran yang dapat peneliti berikan terhadap jalannya aplikasi virtual tour Kampus Universitas Majalengka adalah :

1. Melengkapi Video Streaming setiap Fasilitas

2. Video dapat di simpan commpres lebih kecil lagi agar aplikasi tidak besar

\section{DAFTAR PUSTAKA}

F Bailly, B McClendon, 2011. Virtual tour of userdefined paths in a geographic information system. United States Patent.

FR Daud, V Tulenan, XBN Najoan, 2016. Virtual Tour Panorama 360 Derajat Kampus Universitas Sam Ratulangi Manado. Jurnal Informatika UNSRAT.

Hofstetter (2001). Multimedia Literacy McGrawHill, Inc. Professional Book Group 11 West 19th Street New York, NY United States.

Irwan dan Asep, 2019. Mengenal 6 Bidang Kegunaan dari Penggunaan Perangkat Virtual Reality (VR)

Osman, Wahab dan Ismail 2009. Development and Evaluation of an Interactive 360 Virtual Tour for Tourist Destinations. Journal of Information Technology Impact JITI.

Riyadi, F.S, dkk, 2017. Aplikasi 3D Virtual Reality Sebagai Media Pengenalan Kampus Politeknik Negeri Indramayu Berbasis Mobile. Jurnal Informatika dan Komputer JIKO.

Sherman WR, Craig AB (2003). Understanding Virtual Reality Interface, Application, and Design. A volume in The Morgan Kaufmann Series in Computer Graphics Book Second Edition.

Trieddiantoro, P. H. 2015. Efektivitas Media Grafis dan Virtual Reality dalam Persepsi Ruang Gereja Utama The Church Of Light. Universitas Gajah Mada Yogyakarta.

Vaughan, 1998. Multimedia making it work, McGraw-Hill, Inc. Professional Book Group 11 West 19th Street New York, NY United States ISBN:978-0-07-882552-1. 